\title{
PARISSCHOQL OF ECONOMICS
}

WORKING PAPER Nº 2010 - 45

Advertising and R\&D:

Theory and evidence from France

Philippe Askenazy

Thomas Breda

Delphine Irac

JEL Codes: D4, 031, D12

Keywords: advertising, innovation, competition, Lerner

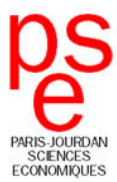




\section{Advertising and R\&D: Theory and Evidence from France ${ }^{1}$}

Philippe Askenazy. Paris School of Economics-CNRS, IZA and Banque de France

Thomas Breda, Paris School of Economics-ENS

Delphine Irac, Banque de France

December 2010

\footnotetext{
${ }^{1}$ The authors would like to thank Philippe Aghion, Catherine Bobtcheff, Daniel Cohen, Bruno Jullien for stimulating comments on previous versions and participants to seminars at the Banque de France, Paris School of Economics, and the AFSE congress. Philippe Askenazy thanks the financial support of the Cepremap.
} 
Abstract: This paper exploits a unique panel of 59,000 French firms over 1990-2004 to investigate the interactions between $\mathrm{R} \& \mathrm{D}$, advertising and the competitive environment. The empirical findings confirm the predictions of a dynamic model that complements results known in static frameworks. First, more competition pushes Neck and Neck firms to advertise more to attract a larger share of consumers on their products or services. Second, for a given competitive environment, quality leaders spend more in advertising in order to extract maximal rents; thus, lower costs of ads may favor R\&D.

Keywords: advertising, innovation, competition, Lerner.

J.E.L. classification: D4, O31, D12. 


\section{Introduction}

In developed countries, both $\mathrm{R} \& \mathrm{D}$ and advertising expenditures are massive, e.g. above $2 \%$ of the GDP in the US. They are two key engines for firms to escape competition through a quality advantage or a better attraction power toward consumers. This paper exploits a large panel dataset of French firms to investigate the joint decision for R\&D and advertising efforts of firms according to the competitive environment. The empirics support the predictions of an original theoretical model.

This issue is related to distinct literatures that analyze the relations between competition and, on the one hand R\&D, or on the other hand, advertising, and the connections between advertising and $R \& D$ :

Though in-depth firm-level empirical investigations are relatively scarce, it seems well established that a more competitive environment induces firms to advertise more (see Bagwell 2005 for a review). Advertising enables to acquire a reputation or to publicize a better quality, intensity in innovation or even fashionableness of products or services. Firms use advertising to deter and accommodate entry and induce exit (Doraszelski and Markovich, 2007). Advertising seems to have clear positive consequences on firms' revenues or profits.

Aghion et al. (2005) summarize, in a unified framework, classic arguments of the controversy Schumpeter versus Arrow. They show an "escape competition" effect of R\&D, whereby competition exerts pressure on firms to spend in $R \& D$ in order to strengthen their technological and market position. But when it is too harsh, it challenges incentives to innovate.

The interplay between $\mathrm{R} \& \mathrm{D}$ and advertising is more ambiguous. If the returns associated to advertising are higher than returns on $\mathrm{R} \& \mathrm{D}$, favoring advertising may induce a substitution and thus a reduction of the R\&D effort. This mechanism should be strengthened when firms face credit constraints or have to compel with short-run objectives. But, advertising and $\mathrm{R} \& \mathrm{D}$ may be complements. Advertising should be associated with improving quality, since a famous firm is reluctant to lose its reputation by offering an odd or outdated product (Fogg-Meade 1901). The Milgrom and Roberts (1986) model of advertising as a signaling tool shows that higher quality firms advertise more. Advertising may be more efficient if the firm proposes innovative or less costly goods or services (Nelson 1974, Fluet and Garella 2002). New opportunities of advertising may help to improve the 
information of consumers on the true quality of firms output, favouring ex ante incentives to improve quality. Advertising may also generate short-term rents that help to finance long-run investments including through $R \& D$. These arguments provide explanations for the high advertising spending in some R\&D intensive sectors, like drugs (Matraves, 1999). In addition, Grossmann (2008) argues that advertising also increases sunk costs and makes entry more difficult. This in turn induces higher market concentrations with larger firms and enhances $R \& D$ investments of insider firms-since $R \& D$ is more profitable to large firms that are able to spread R\&D costs over higher sales-. However, we can reverse the argument: if incumbents are more innovative firms, barriers generated by advertising may reduce the global $\mathrm{R} \& \mathrm{D}$ effort.

Our paper extends these strands of literature: we build a model that encompasses both the static and dynamic interactions between $\mathrm{R} \& \mathrm{D}$, advertising and competitive environment. The model is composed of two blocks. The static one replicates standard results and is then plugged into a dynamic environment. In a given sector, we consider two firms that compete on a market composed of a continuum of consumers. Two shares of the latter have a preference for the product from each firm. The lower these shares, the lower the differentiation, the higher the proportion of undecided consumers and then the larger the room for price competition between the duopolists. The two firms could use costly advertising to convince undecided consumers. The sector is either leveled - both firms are technologically Neck-and-Neck and thus have a similar quality level (and production costs) - or unleveled - one firm being a quality leader and the other one a quality follower. In order to introduce a dynamic trade-off between innovation and preference advantages for firms, this first block of the model is plugged into a quality ladder version of the Aghion et al. (2005) framework. It allows us to endogenize the relationships between competition, advertising and $\mathrm{R} \& \mathrm{D}$ decisions.

Our model provides two main predictions and a conditional prediction. First, for a given competitive environment, quality leaders spend more in advertising than Neck and Neck firms or quality followers; they extract maximal rents from their twofold monopolist positions (in preferences and in quality). There is thus a dynamic complementarity between current advertising and past $\mathrm{R} \& \mathrm{D}$ efforts that stochastically determines the innovation position of the firms. Second, more competition pushes Neck and Neck firms to advertise more in order to attract the larger share of consumers on their products or services. More generally, endogenizing the state of a sector leveled versus unleveled yields 
a positive monotonic relationship between competition toughness and advertising expenditures when cost of ads is moderate. Third, in this case, a lower cost of advertising may stimulate R\&D.

Using a large unbalanced panel of around 59,000 French firms over the 1990-2004 period, we test most of these assertions. The Centrale des Bilans database from the Banque de France provides very detailed data on firm performance and firm expenditures or investments including $R \& D$ and advertising. Within sectors, most productive firms seem to spend more in advertising. Similarly, current advertising spending is positively correlated to past $R \& D$ efforts. These results are consistent with a dynamic complementarity between R\&D and advertising. Estimations also support the monotonic impact of competition on advertising.

This article is organized as follows. Section 2 lays out the basic theoretical static framework. Section 3 introduces the dynamic R\&D process and studies the impact of advertising costs on the flows of innovation. Our main predictions are then derived analytically from this model. Section 4 provides a description of the data and presents our main empirical findings. Section 5 concludes with directions for further research.

\section{Advertising and competition without R\&D dynamics}

This section presents a static theoretical framework to capture the basic connections between competition and advertising for a given technological level of firms. The dynamic interaction with $R \& D$ will be dealt with in section 3 .

\subsection{Basic market structure and quality}

We consider markets as duopolies with firms A and B producing differentiated goods or services. The market can be in a Neck and Neck situation where there is no quality gap between $\mathrm{A}$ and $\mathrm{B}$ or in an unleveled situation where a quality leader (say A) and a follower (say B) coexist.

To structure the discussion, we introduce hedonic indexes of quantities. Hedonic indexes -volume and price- adjust for quality (J. Triplett, 2004). For example, a twomegahertz chipset will be considered equivalent to two one-megahertz chipsets: the hedonic factor is thus 2 . Let $x$ and $\hat{x}$ denote respectively the volume and the hedonic volume; let $p$ and $\hat{p}$ be respectively the price and the hedonic price. 
In the leader-follower case, the leader enjoys a quality gap for similar production costs $c$ : it produces goods with a better quality with a given hedonic factor $1+\epsilon$. We assume that $\epsilon$ is small, so we will work, from herein, with first order terms in $\epsilon$.

Without loss of generality, in the Neck and Neck case, we take the normalization $x_{A}=\hat{x}_{A}, x_{B}=\hat{x}_{B}, p_{A}=\hat{p}_{A}$ and $p_{B}=\hat{p}_{B}$. Then, in the leader-follower case, if for example $A$ is the leader: $\hat{x}_{A}=x_{A}(1+\epsilon), x_{B}=\hat{x}_{B}, \hat{p}_{A}=p_{A} /(1+\epsilon)$ and $p_{B}=\hat{p}_{B}$. Note that we have always $p x=\hat{p} \hat{x}$.

\subsection{Consumers}

We assume that $\epsilon$ also represents the ex ante valuation advantage firms have on specific consumers. These consumers have an initial preference for the goods from A or B. Examples include the wine vs. beer US market of alcohol: recent Gallup polls show that upper-class male Americans that are above 45 and very fond of European culture give a prominent place to wine whereas less well-to-do and younger drinkers favor beer. Inbetween these two categories, people may be classified as indifferent. Segmentation of consumers can also come from geographic constraints, e.g. customers prefer to buy in stores located in their neighborhood. Similarly, artistic professions favor Mac computers whereas scientific professions are more inclined to buy PC, with a priori neutral users in between. We formalize this ex ante inclination of consumers by the existence of segments of captive consumers. The size of these segments is inversely proportional to the degree of competition. To escape competition on the non captive segments, firms can advertise to attract a share of the initially neutral consumers, but also some consumers that ex ante prefer the other good.

Formally, consider a continuum of consumers of mass one indexed by $i$. Their utility follows:

$$
u_{i}=\int_{0}^{1} \ln x_{i j} d j
$$

where $x_{i j}$ is the aggregate of two perfect substitutes A and B from two firms on the market $j$ defined by :

$$
x_{i j}=(1+\epsilon)^{k_{i j} / 2} \hat{x}_{A j}+(1+\epsilon)^{-k_{i j} / 2} \hat{x}_{B j}
$$

where $k_{i j}$ takes value in $\{-1,0,1\}$. We assume that firms can discriminate consumers according to their ex post preferences. 


\subsubsection{Without advertising}

On each market, without loss of generality, consumers can be aligned on the segment $[0,1]$ by increasing order of preference for good B. Because there is no advertising, ex post preferences are the ex ante preferences. The fraction $f_{j} \in[0,1 / 2]$ of non indifferent consumers is defined such as:

$$
k_{i j}=\left\{\begin{array}{lll}
1 & \text { if } & i \in I_{A}=\left[0, f_{j}\right] \\
0 & \text { if } \left.\quad i \in I_{0}=\right] f_{j}, 1-f_{j}[ \\
-1 & \text { if } \quad i \in I_{B}=\left[1-f_{j}, 1\right]
\end{array}\right.
$$

Figure 1 provides an illustration of the distribution of preferences.

The log-preference assumption made in the first equation implies that individuals spend the same amount on each basket $x_{j}$. We normalize this common amount to unity by using expenditure as numeraire for the prices $p_{A j}$ and $p_{B j}$ at each date. Thus each consumer $i$ chooses $\hat{x}_{A j}$ and $\hat{x}_{B j}$ to maximise $x_{i j}$ subject to the budget constraint : $p_{A j} x_{A j}+p_{B j} x_{B j}=\hat{p}_{A j} \hat{x}_{A j}+\hat{p}_{B j} \hat{x}_{B j}=1$. The demand function facing firm $\mathrm{A}$ is then:

$$
\hat{p}_{A j} \hat{x}_{A j}=\left\{\begin{array}{lll}
1 & \text { if } & \hat{p}_{A j} / \hat{p}_{B j}<(1+\epsilon)^{k_{i j}} \\
1 / 2 & \text { if } & \hat{p}_{A j} / \hat{p}_{B j}=(1+\epsilon)^{k_{i j}} \\
0 & \text { if } & \hat{p}_{A j} / \hat{p}_{B j}>(1+\epsilon)^{k_{i j}}
\end{array}\right.
$$

The demand function facing firm B is trivially obtained by inverting A and B in the expression above.

Figure 1: Initial distribution of consumers valuation advantage, $k_{i j}$, given to good A

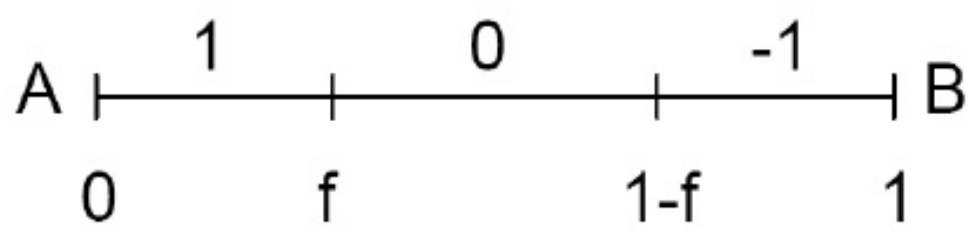

We drop the $\mathrm{j}$ subscript in the remaining of the text.

\subsubsection{With advertising}

Assume now that firms are given the opportunity to advertise their product. Advertising is viewed as a mean of modifying consumers' preferences by affecting their marginal 
Figure 2: Advertising and consumers valuation advantage, $k_{i j}$, given to good $\mathrm{A}$

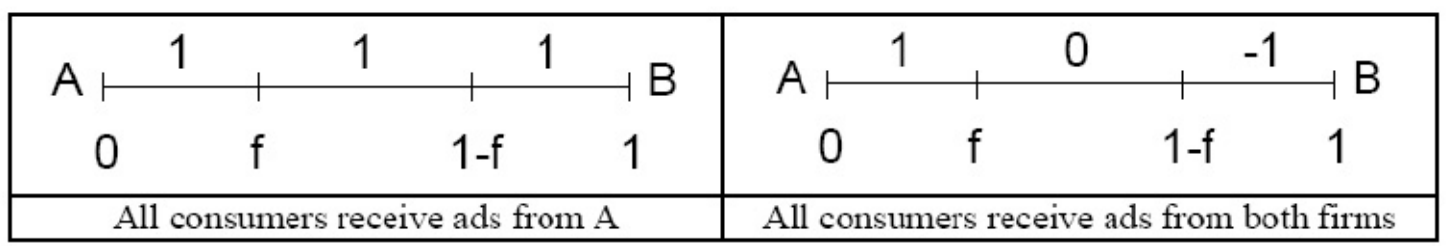

rate of substitution; i.e. ads are persuasive and informative. We model advertising ${ }^{1}$ ac- $^{-}$ cording to the following stylized assumptions:

H1a: If a consumer receives ads from only one firm, her preferences are biased in favor of the product of this firm.

H1b: If a consumer receives ads from the two firms, she comes back to her ex ante preferences.

H2a: Each firm chooses a certain probability $q_{A}\left(\operatorname{resp} q_{B}\right)$ to reach a consumer by advertising. Firms cannot target their ads; This is consistent with the fact that advertising expenditures are primarily in general media (Bagwell, 2005).

H2b: Each firm incurs a cost proportional to $q$, say $\phi q$ for advertising, with $\epsilon / 2<\phi<\epsilon$.

Recall that $\epsilon$ is small, so we work with first order terms in $\epsilon$. Consequently: $(1+\epsilon)^{2}=$ $1+2 \epsilon, 1 /(1+\epsilon)=1-\epsilon$ and $1 /(1+\epsilon)^{2}=1-2 \epsilon$. Chart 2 sums up the marginal rate of substitution (MRS) in two polar cases.

\subsection{Firms: equilibrium prices and profits}

\subsubsection{Without advertising}

Firms use labor as the only input, according to a constant-return production function, and take the wage rate as given. The cost of producing one unit of non-hedonic quantity of good is the same for both firms and is denoted $c$. This unit cost of production $c$ of the two firms in an industry is independent of the quantities produced.

Firms are supposed to be able to price discriminate consumers according to their ex post preferences. They may use for example price promotion for new clients or fidelity cards. Duopolies compete in prices for each consumer, arriving at a Bertrand equilibrium. We now derive the explicit form of prices and profits depending on the technology configuration of the market.

\footnotetext{
${ }^{1}$ For alternative models of advertising in a duopoly framework, see Schoonbeek et al (2007) or Piga (2000).
} 
Throughout the text, subscript 1 will refer to the leader, subscript -1 to the follower, whereas subscript 0 refers to Neck and Neck firms.

\section{a) leveled sector}

In this case, firms are Neck and Neck and production costs are equal for similar quality. On $I_{0}$, due to Bertrand competition, firms will trivially set their price equal to their cost $c$ and make no profit. On $I_{A}$, firm A will use its comparative advantage and choose the maximum price such as firm $\mathrm{B}$ cannot steal the market $I_{A}$ from A without making a negative profit. That is, $p_{A, I_{A}}=c \times(1+\epsilon)$. Firm B acts on $I_{B}$ as $\mathrm{A}$ on $I_{A}$ and gets this market. The infinitesimal profit made on each $i \in[0,1]$ is $\Pi_{A, i}=p_{A, i} x_{A, i}-c x_{A, i}$. Given that $p_{A, i} x_{A, i}=1, \Pi_{A, i}=1-\frac{c}{p_{A, i}}$ if $i$ chooses to buy firm A's good. Finally, since we work with first order terms in $\epsilon$, the overall profit flow of firms $\mathrm{A}$ and $\mathrm{B}$ in the neck and neck case is:

$$
\Pi_{0}=f\left(1-\frac{1}{1+\epsilon}\right)=f \epsilon
$$

\section{b) unleveled sector}

In this second case, one of the two firms is leader and has a hedonic quality advantage equal to $1+\epsilon$. Without loss of generality, we assume that when the sector is unleveled, firm A is the leader and firm B the follower. Again, on each segment, firm A will use its comparative advantage and choose the maximum price such as firm B cannot steal the market without making a negative profit. On $I_{A}$, firm A cumulates its quality advantage and the consumers' preference advantage. Hence, firm A prices $\hat{p}_{A, I_{A}}=c(1+\epsilon)$ i.e. $p_{A, I_{A}}=c(1+2 \epsilon)$. Similarly, $p_{A, I_{0}}=c(1+\epsilon)$ and $p_{A, I_{B}}=c$. Firm A gets the segments $I_{A}$ and $I_{0}$ and share with firm B the segment $I_{B}$ (since the MRS is equal to the ratio of prices) and do not make any profit on this segment. The follower total profit $\Pi_{-1}$ is equal to 0 and, since we work with first order terms in $\epsilon$, the leader's total profit is:

$$
\Pi_{1}=f\left(1-\frac{1}{1+2 \epsilon}\right)+(1-2 f)\left(1-\frac{1}{1+\epsilon}\right)=2 f \epsilon+(1-2 f) \epsilon=\epsilon
$$

\subsubsection{With advertising}

The equilibrium prices and profits depend on the amount of advertising realized by each firm which is function of the cost of advertising $\phi$. We have again to separate the two states of the sector. This framework covers two main views of advertising. In an unleveled sector, ads help the leader to provide information to neutral consumers and thus to expand 
its profitable market share. In a leveled sector, both firms use ads to challenge the market positions.

\section{a) leveled sector}

Firms A and B are Neck and Neck. They choose their probability $q_{A}$ and $q_{B}$ to reach a consumer. Their game is formally similar to a mixed-strategy game with $q=0$ and $q=1$ the pure strategies. So, their choices are also the mixed Nash equilibrium of this latter game. On its ex ante captive segment, firm A can sell above its marginal cost only to consumers that have not received an ad from B or that have received ads from both firms. Its sales profits are then $f \epsilon\left(1-q_{B}+q_{B} q_{A}\right)$. Similarly, profits of $\mathrm{A}$ on the central segment are $(1-2 f) \epsilon\left(q_{A}-q_{B} q_{A}\right)$ and on the B captive segment $f \epsilon\left(q_{A}-q_{B} q_{A}\right)$. The profits of A are then $\pi_{A}=\epsilon\left[(1-f) q_{A}-(1-2 f) q_{A} q_{B}+f\left(1-q_{B}\right)\right]-\phi q_{A}$. Assume that A chooses a mixed strategy; the support of this strategy is $q_{A}=0$ and $q_{A}=1$. Consequently the Nash mixed strategy for B is $q_{B}$ such that $\left(\pi_{A} \mid q_{A}=0\right)=\left(\pi_{A} \mid q_{A}=1\right)$ i.e. $f\left(1-q_{B}\right)=f+(1-2 f)\left(1-q_{B}\right)+f\left(1-q_{B}\right)-\phi / \epsilon$, or $(1-f)-(1-2 f) q_{B}-\phi / \epsilon=0$. Therefore, we have to distinguish 2 cases:

- if $\epsilon / 2<\phi<(1-f) \epsilon$, then the Nash equilibrium is the symmetric strategy:

$$
q_{0}=q_{A}=q_{B}=\frac{1-f-\phi / \epsilon}{1-2 f} \in[0,1]
$$

- if $\epsilon(1-f)<\phi<\epsilon$, then the Nash equilibrium is the symmetric strategy:

$$
q_{0}=q_{A}=q_{B}=0
$$

\section{b) unleveled sector}

We first prove that the follower has no interest to advertise. Assume that the follower makes some ads $q>0$. By construction, its ads are more efficient when the leader does not advertise ${ }^{2}$. Take this case: the follower convinces a share $q$ of consumer; however, the follower has to adjust its hedonic price to a level for which the technological leader makes no profits i.e. $c$; so the follower makes also no sales profits and incurs a cost $\phi q>0$ for advertising. So even in the most favorable case for the follower, the profits of the follower are negative when $q$ is positive. Consequently, the follower advertising probability is $q_{-1}=0$ and its profit is $\Pi_{-1}=0$.

Now consider the leader. It chooses a level of advertising q in order to maximize its profits. The leader's net revenue is $2 f \epsilon$ on its ex ante captive segment; $(1-2 f)(2 \epsilon q+\epsilon(1-q))$

\footnotetext{
${ }^{2}$ since $\pi_{-1}\left(q_{1}, q_{-1}\right) \leq \pi_{-1}\left(0, q_{-1}\right) \leq 0$; let us note that: $\pi_{-1}(0,0)=0$ and $\pi_{-1}\left(0, q_{-1}\right)=-q_{-1} \phi$
} 
on the ex ante neutral segment; and $2 f \epsilon q$ on the ex ante captive segment of the follower. This implies:

$$
\Pi_{1}(q)=2 f \epsilon+2(1-2 f) \epsilon q+(1-2 f) \epsilon(1-q)+f \epsilon(1-q)-\phi q=\epsilon+q(\epsilon-\phi) .
$$

Now because $\epsilon>\phi$, the leader maximizes its profits when $q=q_{1}=1$ i.e. $\Pi_{1}=2 \epsilon-\phi$.

Table 1 summarizes these results and figure 3 depicts the leader's and Neck and Neck's advertising levels when $\mathrm{f}$ varies between 0 and $1 / 2$ and $\phi=0.6 \epsilon$. Note that $\Pi_{0}$ being equal to $f \epsilon$ or to the product of two positive functions that are increasing with $\mathrm{f}$ is increasing with $\mathrm{f}$.

Table 1: Firms advertising expenditure and profit

\begin{tabular}{|l|l|l|l|}
\hline & Follower & Leader & Neck\&Neck \\
\hline Without ads: & $\Pi_{-1}=0$ & $\Pi_{1}=\epsilon$ & $\Pi_{0}=f \epsilon$ \\
\hline & & & - if $\epsilon / 2<\phi<(1-f) \epsilon:$ \\
With Ads: & $q_{-1}=0$ & $q_{1}=1$ & $q_{0}=(1-f-\phi / \epsilon) /(1-2 f)$ \\
& & & $\Pi_{0}=f \epsilon\left(\frac{\phi / \epsilon-f}{1-2 f}\right)$ \\
& & & - if $(1-f) \epsilon<\phi<\epsilon:$ \\
& $\Pi_{-1}=0$ & $\Pi_{1}=2 \epsilon-\phi$ & $q_{0}=0$ \\
& & & $\Pi_{0}=f \epsilon$ \\
\hline
\end{tabular}

Figure 3: Leader's and Neck and neck's advertising probabilities and profits as a function of competition $(\phi=0.6 \epsilon)$ :
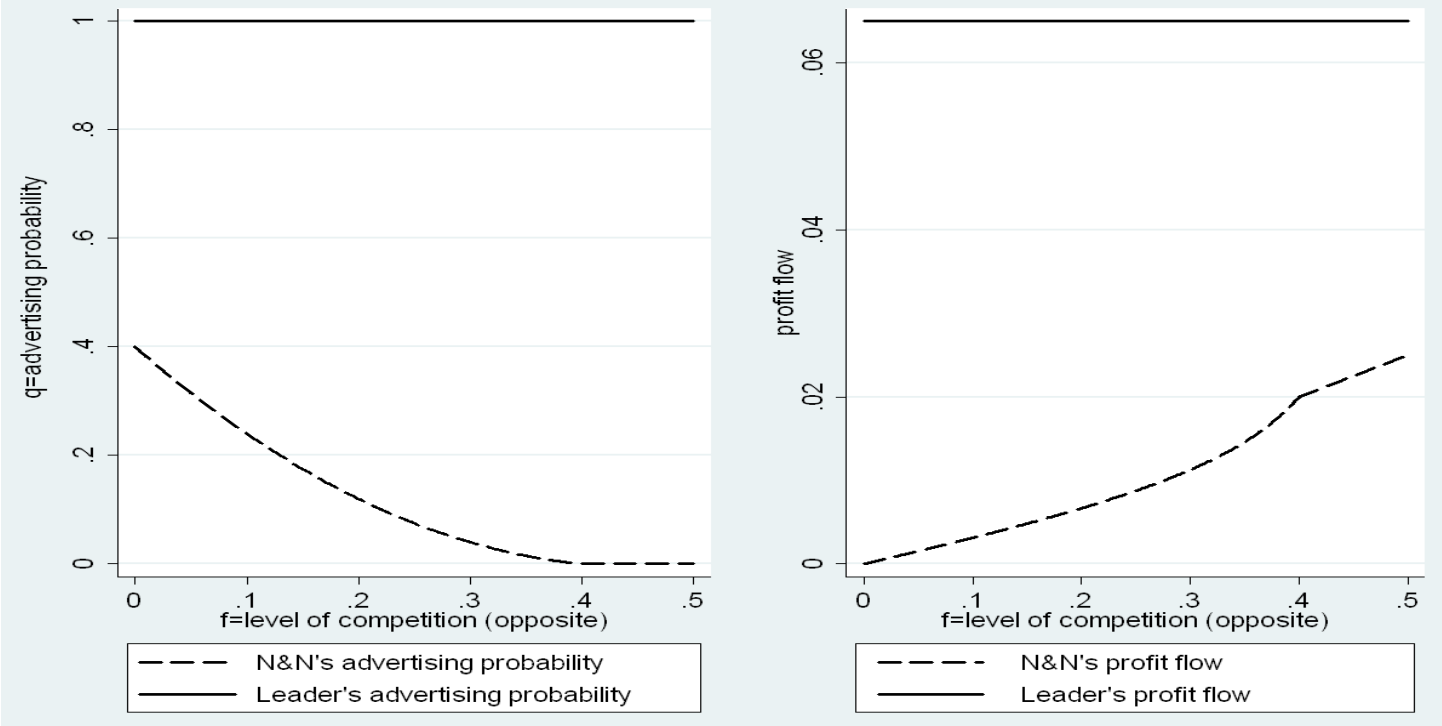
We have thus the following proposition that is consistent with Milgrom and Roberts (1986) findings:

Proposition 1: Advertising expenditures increase with the quality advantage of firms: the quality leader advertises more than the follower and the Neck and Neck; and the Neck and Neck advertises more than the follower.

Intuitively, because it faces lower production costs, the quality leader has interest to try to capture both ex ante neutral and unfavorable segments. In addition it does not face the advertising competition of its competitor. So it advertises more than Neck and Neck firms for a given level of competition $f$. Neck and Neck firms advertise more than followers who do no advertise since they lose money if they do. This leads to results again consistent with the literature (see Bagwell 2005):

Proposition 2: For a given state of the sector (leveled or unleveled) advertising expenditures are increasing with competition. More precisely, $q_{0}$ is decreasing with $f$ and $q_{-1}$ and $q_{1}$ are constant.

Intuitively, when competition is tougher i.e. the ex-ante non-captive markets are large, all firms try to escape competition through an increase in their advertising effort.

Now, computing the aggregated levels of advertising for different degrees of competition and so to determine the relation between advertising and competition requires to determine the proportion of leveled and unleveled sectors for a given degree of competition.

\section{Dynamics of R\&D investment and advertising}

Firms can develop a dynamic strategy to escape competition through becoming a quality leader and thus through innovation. Hence, we have to introduce the dynamics of R\&D investment. The benchmark case of Aghion et al. (2005) framework naturally generates unleveled and Neck and Neck sectors. We develop here a quality ladder version of this framework and plug in this environment the static model of section 2 .

We assume the main subcase of Aghion et al. (2005): knowledge spill-overs between leader and follower are such that the maximum sustainable quality gap is 1, leading to a maximal hedonic advantage equal to $1+\epsilon$. If a firm is one step ahead and it innovates the follower will automatically copy the leader's previous technology and so remain only 
one step behind.

The state of an industry is then fully characterized by a pair of integers $(l, m)$ where $l$ is the leader's technology and $m=1$ is the technology gap of the leader over the follower; $m=0$ when firms are neck and neck. As proved in the previous section, the profit in the industry depends only on the gap $m$ between the two firms and not on absolute levels of technology.

The $\mathrm{R} \& \mathrm{D}$ cost of firm moving one quality step ahead with a Poisson hazard rate of $n$ is $n^{2} / 2$. We call $n$ the "innovation rate" or "R\&D intensity" of the firm. We assume that a follower firm can move one step ahead with hazard rate $h$ even if it spends nothing on $\mathrm{R} \& \mathrm{D}$, by copying the leader's technology. Thus $n^{2} / 2$ is the $\mathrm{R} \& \mathrm{D}$ cost of a follower firm moving ahead with a hazard rate $n+h$. Each innovation step changes the competitive environment and thus cancels the effect of past advertising on consumers' preferences.

\subsection{Bellman equations}

We now derive general equations for R\&D investments. Let $V$ denote the steady state value of the firm. We have the following Bellman equations:

$$
\left\{\begin{array}{l}
r V_{1}=\Pi_{1}+\left(n_{-1}+h\right)\left(V_{0}-V_{1}\right)-n_{1}^{2} / 2 \\
r V_{-1}=\Pi_{-1}+\left(n_{-1}+h\right)\left(V_{0}-V_{-1}\right)-n_{-1}^{2} / 2 \\
r V_{0}=\Pi_{0}+n_{0}\left(V_{1}-V_{0}\right)+\bar{n}_{0}\left(V_{-1}-V_{0}\right)-n_{0}^{2} / 2
\end{array}\right.
$$

The annuity value $r V_{1}$ of currently being a quality leader in an industry with gap 1 at date $t$ equals the current profit flow $\Pi_{1}$ minus the current $\mathrm{R} \& \mathrm{D}$ cost $n_{1}^{2} / 2$, plus the expected capital loss $\left(n_{-1}+h\right)\left(V_{0}-V_{1}\right)$ from having the follower catch up with the leader. Similar arguments lead to equations for the value of a follower and a neck and neck firm.

Given that profitability is only dependent on the gap between leader and follower, no innovation will be undertaken by the leader i.e. $n_{1}=0$. Now, using the fact that each firm chooses its own R\&D intensity to maximize its current value, i.e. to maximize the RHS of the corresponding equation, we obtain the first order conditions:

$$
\left\{\begin{array}{l}
n_{-1}=V_{0}-V_{-1} \\
n_{0}=V_{1}-V_{0} \\
n_{1}=0
\end{array}\right.
$$

According to these first order conditions, an increase in market competition diminishes profits of a leveled firm, and consequently its market value $V_{0}$ decreases. Hence, one could 
expect that an increase in market competition leads to an increase in $n_{0}$ and a decline in $n_{-1}$.

Equations (1) and (2) solve for $n_{0}$ and $n_{-1}$. Eliminating the $V$ 's between these equations yields the reduced form R\&D equations:

$$
\begin{aligned}
& \frac{n_{0}^{2}}{2}+(r+h) n_{0}-\left(\Pi_{1}-\Pi_{0}\right)=0 \\
& \frac{n_{-1}^{2}}{2}+\left(r+h+n_{0}\right) n_{-1}-\left(\Pi_{0}-\Pi_{-1}\right)-\frac{n_{0}^{2}}{2}=0
\end{aligned}
$$

This system is recursive, as the first equation solves for $n_{0}$, and then given $n_{0}$ the second equation solves for $n_{-1}$. We obtain:

$$
\begin{aligned}
& n_{0}=-r-h+\sqrt{(r+h)^{2}+2\left(\Pi_{1}-\Pi_{0}\right)} \\
& n_{-1}=-\left(r+h+n_{0}\right)+\sqrt{\left(r+h+n_{0}\right)^{2}+n_{0}^{2}+2\left(\Pi_{0}-\Pi_{-1}\right)}
\end{aligned}
$$

Using equation (3) to substitute $\left(r+h+n_{0}\right)^{2}$ in equation (4) yields the alternative expression:

$$
n_{-1}=-\left(r+h+n_{0}\right)+\sqrt{(r+h)^{2}+n_{0}^{2}+2\left(\Pi_{1}-\Pi_{-1}\right)}
$$

The R\&D investment $n_{0}$ of a Neck and Neck firm is increasing in $\left(\Pi_{1}-\Pi_{0}\right)$ : the larger the difference between Neck and Neck firms and leader firms profit flows, the larger the incentive for a Neck and Neck firm to become a leader and thus the larger its R\&D investment. Interpretation of equation 4 is also intuitive: for $n_{0}$ given, $n_{-1}$ is increasing in $\left(\Pi_{0}-\Pi_{-1}\right)$; the larger its incentive to catch-up the leader, the greater the follower's R\&D investment. But it requires two successful investments for the follower to become a leader, and its profit in the intermediate situation of Neck and Neck should also matters. This is captured by the presence of $n_{0}$ in equation (5): $n_{-1}$ is decreasing ${ }^{3}$ in $n_{0}$.

The innovation rate of a sector is $2 n_{0}$ if the sector is leveled and $n_{-1}$ if the sector is unleveled. But the average innovation rate of a sector in steady state also depends on the fraction of time a sector spends being leveled or unleveled. Formally, let $\mu_{1}$ (resp. $\left.\mu_{0}\right)$ denote the steady state probability of being an unleveled (resp. neck and neck) industry. During any unit time interval, the steady state probability that a sector moves from being unleveled to leveled is $\mu_{1}\left(n_{-1}+h\right)$, and the probability that it moves in the opposite direction is $2 \mu_{0} \times n_{0}$. In steady state, these two probabilities must be equal:

$$
\begin{gathered}
\mu_{1}\left(n_{-1}+h\right)=2 \mu_{0} n_{0} \\
{ }^{3} \text { Indeed } \partial n_{-1} / \partial n_{0}=-1+n_{0} / \sqrt{(r+h)^{2}+n_{0}^{2}+2\left(\Pi_{1}-\Pi_{-1}\right)}<0 .
\end{gathered}
$$


Because $\mu_{1}+\mu_{0}=1$, this implies that the average flow of innovation is:

$$
I=\mu_{0} 2 n_{0}+\mu_{1} n_{-1}=\mu_{1}\left(2 n_{-1}+h\right)=\frac{4 n_{0} n_{-1}+2 n_{0} h}{2 n_{0}+n_{-1}+h}
$$

\subsection{Competition and advertising}

As in Aghion et al. (2005), the general form of $I$ is an inverted- $U$ shape according to the level of competition. The escape competition effect dominates when competition is not too harsh.

Profit flows of firms A and B calculated in section 2 depend on the degree of competition, the ratio of valuation for goods $\mathrm{A}$ and $\mathrm{B}$ for a consumer in $[0, f]$, the quality gap and the cost of advertising $\phi$. As a consequence, $I$ is a function of exogenous parameters $f, \epsilon, r$ and $h$.

Figure 4 plots the average of innovation and advertising expenditure when $r=0.05$, $h=0.20, \epsilon=0.05$, and the cost of advertising is moderate $(\phi=4 \epsilon / 5=0.04)$.

Innovation appears to be indeed inverted U-shaped and the right side plot exhibits a positive relation between competition and advertising effort. In addition, competition and advertising spending are positively related when the cost of advertising is moderate:

Proposition 3: In the dynamic framework, average advertising expenditures $A=\phi\left(\mu_{0} 2 q_{0}+\right.$ $\left.\mu_{1} q_{1}\right)$ are still increasing with competition.

Proposition 3 is proved in appendix 1.

Remark: Through changes in competition, we may observe a negative relation between innovation flows and advertising efforts. Figure 4 illustrates that when the competitive environment is harsh ( $f$ small), a firm facing even more competition reduces current $\mathrm{R} \& \mathrm{D}$ but increases current advertising. However, this mechanism driven by competition does not mean that advertising and R\&D are substitute. Actually, the static results still hold: for a given competitive environment, innovative firms advertise more and firms innovate more when advertising is possible.

\subsection{Advertising costs and R\&D}

Because of the interplay between R\&D and advertising, changes in the advertising regulation or technologies may alter advertising costs and thus R\&D. For example, Internet has opened a new facility for advertising. On the contrary, some countries heavily regulate 
Figure 4: Competition and average sectoral advertising effort and flow of innovation: simulation results.

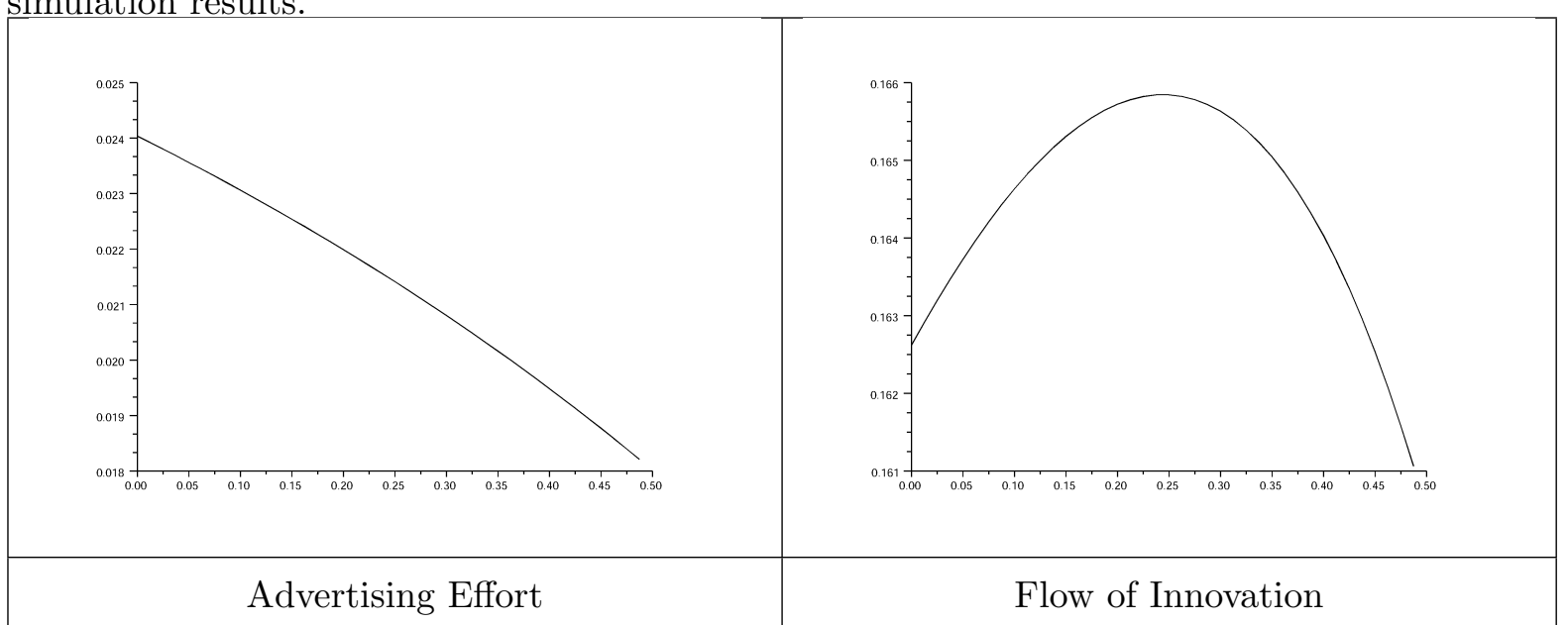

Note: Competition is a decreasing function of the proportion of captive consumers $f$ on the $\mathrm{x}$-axis.

ads in certain media; that is the case in France where the government has recently banished ads on all public TV after 8 pm.

Now, reducing the cost of advertising has the direct effect to stimulate advertising expenditures. But how this additional advertising does affect the firms' R\&D efforts? This crucially depends on the relative effect of decreasing advertising costs on the follower, Neck and Neck and leader expected profits. However, we prove (see appendix) the following partial result:

Proposition 4: The total flow of innovation is decreasing with $\phi$ if competition is not too harsh.

In other words, the less expensive advertising is, the more R\&D. This is true for any degree of competition, that is for any given value of $f$ between $1-\phi / \epsilon$ and 1 . Simulations (see figure 6 in appendix 2) show how $I$ varies when $f$ and $\phi$ vary: $I$ is inverted $\mathrm{U}$ shape as a function of $f$ (on the $\mathrm{x}$ axis) and increases a lot when the cost of advertising is decreased from $\phi=\epsilon=0.05$ to $\phi=\epsilon / 2=0.025$ (y axis).

\section{Empirical evidence}

This section exploits French micro datasets in order to test the main theoretical predictions. The originality of the data is to provide both $R \& D$ investment and advertising 
spending for a large panel of firms. Raw statistics are consistent with the model. Figure 5 plots the average of $R \& D$ and advertising efforts as a function of the 20-ciles of firm Lerners. R\&D effort appears inverted U-shaped in the measure of competition whereas average advertising is clearly increasing with competition.

Figure 5: Competition and advertising and R\&D expenditures: evidence for a panel of French firms.
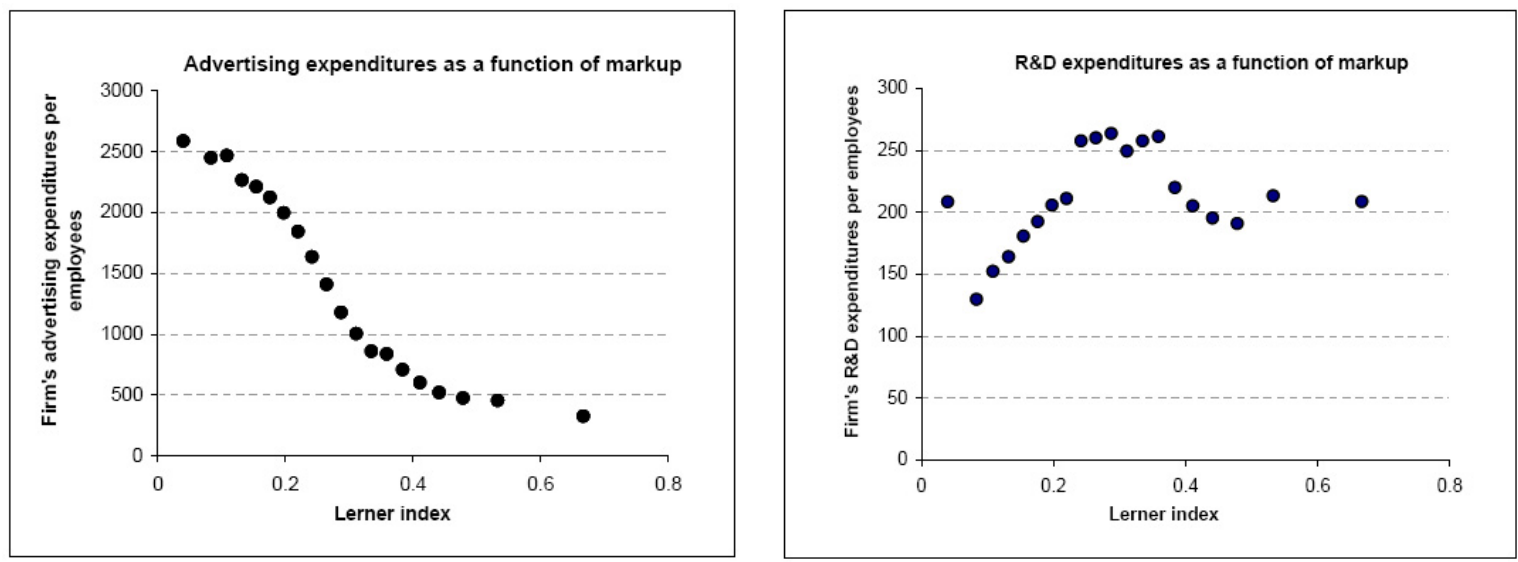

Note: Competition is a decreasing function of the Lerner index on the x-axis.

Source: FIBEN/Centrale des Bilans

We now turn to the presentation of the data sources and then to the econometric estimations.

\subsection{Data}

We use a subset of the FIBEN dataset provided by the Observatoire des entreprises at the Banque de France. Data from FIBEN are collected on a voluntary basis. Clerks in the different local establishments of the Bank of France contact firm to complete a survey. The Fiben database is based on firms tax forms and includes all businesses with more than 500 employees and a fraction of smaller firms. It covers about $57 \%$ of employment for manufacturing but less for service sectors. A subset of FIBEN, the so called Centrale des Bilans contains more detailed information on firms' expenditures that are specifically devoted to increase their potential sales, with two special items on advertising and R\&D expenditures ${ }^{4}$.

\footnotetext{
${ }^{4}$ These items have a precise counterpart in the official accounting plan ( plan comptable général). Advertising comes from category 623 , whereas R\&D expenditures are the sum of elements in categories 61,62 and 64.
} 
The clear value-added of these micro data compared to other sources on $R \& D$ is to include firms that have episodic $R \& D$ and advertising activities or novel firms and to provide in the same time their advertising efforts. R\&D can be considered either as expenditure or as investment in the French legal accounting setting. Broadly speaking, $\mathrm{R} \& \mathrm{D}$ costs concerning a well defined project and yielding almost certain return can be declared as investments whereas $\mathrm{R} \& \mathrm{D}$ expenditures linked to more uncertain projects have to be considered as current expenditures. In this paper, we add these two categories together.

Advertising expenditures in our data is a broad category: it includes the classic ads in various media but also expenditures for exhibits, the publication of catalogs and the organization of public events as well as expenditures due to presents and free samples offered to customers.

A Lerner index for each firm can be built using these data. We only observe sectoral price provided by the INSEE, but we have detailed information on costs. The Lerner index is supposed to measure the market power of the firm by the difference between price and marginal costs (which equals the negative inverse of demand elasticity). Since neither price nor marginal costs are available at the firm level, we compute the index using value-added net of depreciation and provisions minus the financial cost of capital (cost of capital*capital stock) over sales (in line with Aghion et al., 2005). The Fiben database contains very detailed balance sheet information that enables to compute these Lerner indicators. ${ }^{5}$ In our model the Lerner index is decreasing with $f$, the measure of competition.

Using measures of capital stocks in volume that account for differences in the average age of capital ${ }^{6}$, we compute a total factor productivity index (TFP) for each firm based on a revenue function. TFP is computed as the ratio of value added over a Cobb-Douglas combination of labor and capital, where the parameter for labor is firm specific, taken as the time average of the share of the wage bill in value added and the parameter of the capital stock equals one minus the parameter of labor. Note that in our model, all firms

\footnotetext{
${ }^{5}$ Lerner $=($ value added-depreciation-cost of capital.capital stock-provision)/sales Using the standard mnemonics of French tax forms: Lerner=[VA-(AQ+AS+AU+AW+AY-AQ-1-AS-1AU-1-AW-1-AY-1)-0.085.capital-(DR-DR-1)]/FL.

${ }^{6}$ FIBEN includes balance sheet data only; namely, the value of physical assets that it reports is given at historical costs. Using standard methods based on the depreciation rate, we estimate the average age of capital to adjust for this price effect.
} 
have the same technology (same $c$ ) but the leader (say firm A) can set higher prices than Neck and Neck firms on $I_{B}$ and $I_{0}$ due to hedonic advantage. Hence, on average, leaders enjoy higher TFP, based on a revenue function than Neck and Neck firms.

We finally have Lerner index, total R\&D and marketing expenditures available for an unbalanced panel of 59 thousands firms from 1990 to 2004. This final sample contains around 480,000 firm-year observations, the number of firms present each year is around 30,000 and is relatively stable over time. In average a firm is observed in our sample during around 7 years.

Table 2 shows some aggregate descriptive statistics. On average advertising weights about $4.1 \%$ of firm value-added and $\mathrm{R} \& \mathrm{D}$ spending about $1.6 \%$. This last figure is consistent with the national account ratio for market economy.

Table 2: Descriptive statistics for main variables

\begin{tabular}{lllllll}
\hline \hline & Mean & Median & Std. Dev. & First & Last & Number \\
& & & & decile & decile & of obs \\
\hline Value added $\left(1000^{\prime} €\right)$ & 6155.4 & 1296 & 93135.7 & 359 & 7623 & 515,185 \\
Advertising exp. $\left(1000^{\prime} €\right)$ & 253.6 & 3.047691 & 4758.0 & 0 & 117 & 515,185 \\
Advertising exp. $(€)$ per empl. & 1430.0 & 102.8 & 6141.2 & 0 & 3000.1 & 515,185 \\
R\&D exp. (1000'€) & 97.1 & 0 & 4313.1 & 0 & 3.2 & 515,185 \\
R\&D exp. (€) per employee & 226.6 & 0 & 1595.2 & 0 & 63.6 & 515,185 \\
Total factor productivity & .21 & 0.19 & .1108 & .092 & .33 & 436945 \\
Nb of employees & 123 & 33 & 1542 & 9 & 172 & 515185 \\
R\&D stock (€) per employee & 943 & 0 & 9162 & 0 & 832 & 329235 \\
Lerner index & 0.29 & 0.28 & 0.16 & 0.10 & 0.50 & 471,503
\end{tabular}

Value added, advertising expenditure and R\&D expenditure are given in thousands of 2004 euros. Advertising and R\&D expenditure per employee and R\&D stock per employee are given in 2004 euros.

Table 6 in appendix 2 presents the mean of advertising and R\&D by sector. Unsurprisingly, retail trade, food industry and consumer goods exhibit high levels of advertising (more than 2000 Euros per employee); whereas high level of R\&D are observed in cars, equipment goods and energy sectors. One manufacturing sector has a very high level of advertising compared to R\&D: food industry, which partly reflects the downstream margin effects. 


\subsection{Results}

Two key predictions of the model can be statistically tested. First, our model shows that there is an increasing relationship between advertising and competition. Second, the quality leader always has a level of advertising that is higher than the rest of the firms. Three types of estimations are applied on the panel data: a simple OLS, a firm fixed effect estimator and a random effect estimation. 114 industry dummies, firm size and year fixed effects have been included as controls in all specifications. All standard errors are computed using the standard Huber-White sandwich procedure.

Table 2 tests the first prediction. Two alternative specifications are used: The measure of the inverse of competition is either a firm-level Lerner or a industry-level Lerner. To cope with simultaneity issue, the firm-level index is lagged. Advertising effort is measured as the ratio of advertising in 2004 Euros over the number of employees in the firm. Controlling for years and for firm size, the regression coefficient between advertising and the inverse of competition is clearly negative. Note that these results are not driven by large firms since they still hold when restricting the sample to firms below 250 employees. The magnitudes of the estimated coefficients are similar for the 3 alternative estimators. An increase of one standard deviation of the Lerner index is associated with significant additional advertising expenditures: about 500 euros per employee.

Tables 3 and 4 test the second prediction. In order to identify potential leaders, we first make the reasonable assumption that leaders enjoy a better total factor productivity (TFP). For the OLS estimations, a leader should be considered as the leader in its industry for a given date, so we add detailed industries*date dummies as references in the regressions. Table 3 shows that higher TFP (coincident or lagged) is correlated with higher advertising. Here again the estimated coefficient is large; a 10\% rise in TFP is associated with an increase in advertising expenditure ranging from 250 to 420 euros per employee.

Assuming that the technological position can also be described by cumulative past $R \& D$ efforts, we build a rough proxy for a $R \& D$ stock by adding $R \& D$ expenditures over the past 4 years. The average R\&D stock is around 950 Euros per employee. Table 4 shows that higher lagged $R \& D$ stock per employee is correlated with higher advertising. Unsurprisingly, the relationship between current R\&D stock and advertising is much more blurred, since this former includes current R\&D expenditures which should equal 0 for the quality leader according to the model. 
Table 3: Advertising and competition. 1990-2004.

\begin{tabular}{lllllll}
\hline \multicolumn{5}{c}{ Dependent variable: advertising expenditure (in thousands 2004 euros) per employee } \\
\hline & $1:$ OLS & $2: \mathrm{FE}$ & $3: \mathrm{RE}$ & $4: \mathrm{OLS}$ & $5: \mathrm{FE}$ & $6: \mathrm{RE}$ \\
\hline Lerner industry 114 (lagged) & -3.719 & -2.341 & -5.700 & & & \\
& $(4.30)^{* *}$ & $(4.89)^{* *}$ & $(28.56)^{* *}$ & & & \\
Lerner firm (lagged) & & & & -3.006 & -1.431 & -2.832 \\
& & & & $(39.77)^{* *}$ & $(12.31)^{* *}$ & $(31.29)^{* *}$ \\
Nb of employees (thousands) & 0.059 & -0.024 & 0.013 & 0.097 & -0.083 & 0.046 \\
& $(8.92)^{* *}$ & $(2.72)^{* *}$ & $(2.26)^{*}$ & $(11.39)^{* *}$ & $(1.16)$ & $(3.71)^{* *}$ \\
Constant & 3.361 & 2.952 & 3.989 & 3.116 & 2.683 & 3.106 \\
& $(13.05)^{* *}$ & $(20.38)^{* *}$ & $(48.10)^{* *}$ & $(71.28)^{* *}$ & $(56.82)^{* *}$ & $(56.25)^{* *}$ \\
\hline Years & YES & YES & YES & YES & YES & YES \\
114 industry dummies & YES & YES & YES & YES & YES & YES \\
\hline Observations & 476418 & 476418 & 476418 & 470128 & 471503 & 471503 \\
Number of firms & 59554 & 59554 & 59554 & 59554 & 59073 & 59073 \\
R-squared & 0.07 & 0.02 & & 0.07 & 0.02 & \\
\hline
\end{tabular}

* significant at 5\%; ** significant at $1 \%$, robust $\mathrm{t}$ and $\mathrm{z}$ statistics in parentheses.

Table 4: Advertising and technological position. 1990-2004.

\begin{tabular}{lllllll}
\hline \multicolumn{5}{c}{ Dependent variable: advertising expenditure (in thousands 2004 euros) per employee } \\
\hline TFP & $1:$ OLS & $2: \mathrm{FE}$ & $3: \mathrm{RE}$ & $4: \mathrm{OLS}$ & $5: \mathrm{FE}$ & $6: \mathrm{RE}$ \\
& 4.244 & 2.932 & 2.765 & & & \\
& $(44.66)^{* *}$ & $(10.47)^{* *}$ & $(11.65)^{* *}$ & & & \\
TFP (lagged) & & & & 4.097 & 2.827 & 2.594 \\
& & & & $(38.90)^{* *}$ & $(9.07)^{* *}$ & $(10.11)^{* *}$ \\
Nb of employees (thousands) & 0.060 & -0.021 & 0.008 & 0.061 & -0.021 & 0.010 \\
& $(8.66)^{* *}$ & $(3.63)^{* *}$ & $(1.60)$ & $(8.27)^{* *}$ & $(3.42)^{* *}$ & $(1.84)$ \\
Constant & 0.609 & 1.595 & 1.633 & 0.703 & 0.182 & 1.660 \\
& $(28.11)^{* *}$ & $(24.10)^{* *}$ & $(26.21)^{* *}$ & $(29.48)^{* *}$ & $(2.61)^{* *}$ & $(25.70)^{* *}$ \\
\hline (industry114, year) dummies & Yes & No & No & Yes & No & No \\
Year & No & Yes & Yes & No & Yes & Yes \\
\hline Observations & 436945 & 436945 & 436945 & 378809 & 378809 & 378809 \\
Number of firms & 52885 & 52885 & 52885 & 49818 & 49818 & 49818 \\
R-squared & 0.08 & 0.02 & & 0.09 & 0.02 & \\
\hline
\end{tabular}

* significant at $5 \%$; ** significant at $1 \%$, robust $\mathrm{t}$ and $\mathrm{z}$ statistics in parentheses. 
Table 5: Advertising and gross R\&D stock. 1990-2004.

\begin{tabular}{lllllll}
\hline \multicolumn{6}{l}{ Dependent variable: advertising expenditure (in thousands 2004 euros) per employee } \\
\hline & $1: \mathrm{OLS}$ & $2: \mathrm{FE}$ & $3: \mathrm{RE}$ & $4: \mathrm{OLS}$ & $5: \mathrm{FE}$ & $6: \mathrm{RE}$ \\
\hline R\&D stock per employee & 0.037 & 0.006 & 0.011 & & & \\
& $(29.39)^{* *}$ & $(0.75)$ & $(1.52)$ & & & \\
R\&D stock per employee (-1) & & & & 0.034 & 0.023 & 0.018 \\
& & & & $(23.68)^{* *}$ & $(2.76)^{* *}$ & $(1.89)$ \\
Nb of employees (thousands) & 0.058 & -0.013 & 0.016 & 0.058 & -0.014 & 0.015 \\
& $(7.21)^{* *}$ & $(1.83)$ & $(2.37)^{*}$ & $(6.79)^{* *}$ & $(1.49)$ & $(2.16)^{*}$ \\
Constant & 1.566 & 0.811 & 0.871 & 1.677 & 0.788 & 0.838 \\
& $(0.00)$ & $(25.30)^{* *}$ & $(23.87)^{* *}$ & $(134.86)^{* *}$ & $(23.41)^{* *}$ & $(22.20)^{* *}$ \\
\hline (industry114, year) dummies & Yes & No & No & Yes & No & No \\
\hline Year & No & Yes & Yes & No & Yes & Yes \\
\hline Observations & 329235 & 329235 & 329235 & 277790 & 277790 & 277790 \\
Number of firms & 48705 & 48705 & 48705 & 43461 & 43461 & 43461 \\
R-squared & 0.08 & 0.02 & & 0.09 & 0.02 & \\
\hline
\end{tabular}

* significant at $5 \%$;* significant at $1 \%$, robust $\mathrm{t}$ and $\mathrm{z}$ statistics in parentheses.

These findings seem to clearly support a complementarity between advertising efforts and the past innovation efforts of firm or their current technological level, in line with the prediction of our model.

Note that the model has no clear prediction on the relation between current $R \& D$ and current advertising expenditures. The leader does not spend on R\&D and strongly advertise whereas followers and Neck and Neck firms spend on R\&D but advertise less strongly. This suggests a negative relation. But the R\&D expenditures of the followers and Neck and Neck crucially depend on the degree of competition, which makes the overall relation theoretically unclear. Our data are not inconsistent with the latter: the empirical correlation between current $\mathrm{R} \& \mathrm{D}$ and current advertising efforts is negative but non robust.

\section{Conclusion}

We have studied the interactions between competition, R\&D and advertising through a static and a dynamic frameworks. Empirical evidence using a large dataset on French 
firms supports the two main predictions of our theoretical model: First, advertising efforts are increasing with competition. Second, qualitative leaders spend more on advertising; intuitively, leaders enjoy higher advertising returns by capturing the segment of neutral consumers and those who ex ante prefer the follower products. This last result suggests that the lower the cost of advertising the higher the incentive of becoming a leader. As a consequence, reduced advertising cost may improve innovation. An extension of this paper will be to investigate such a mechanism. Empirically, this would require identifying structural reforms impacting advertising costs or technological shocks. The emergence of massive advertising on internet would offer a relevant natural experiment when data will be available. 


\section{References}

[1] Aghion, P., N. Bloom, R. Blundell, and R. Griffith (2005): "Competition and Innovation: An Inverted-U Relationship," Quarterly Journal of Economics, 120(2), $701-728$.

[2] Bagwell, K. (2005): "The Economic Analysis of Advertising," Handbook of Industrial Organization, 3.

[3] Doraszelski, U., and S. Markovich (2007): "Advertising dynamics and competitive advantage," The RAND Journal of Economics, 38(3), 557-592.

[4] Fluet, C., and P. Garella (2002): "Advertising and prices as signals of quality in a regime of price rivalry," International Journal of Industrial Organization, 20(7), 907-930.

[5] Fogg-Meade, E. (1901): "The Place of Advertising in Modern Business," The Journal of Political Economy, 9(2), 218-242.

[6] Grossmann, V. (2008): "Advertising, in-house R\&D, and growth," Oxford Economic Papers, 60(1).

[7] Matraves, C. (1999): "Market structure, R\&D and advertising in the pharmaceutical industry," Journal of Industrial Economics, 47(2), 169-194.

[8] Milgrom, P., And J. Roberts (1986): "Price and advertising signals of product quality," The Journal of Political Economy, 94(4), 796-821.

[9] Nelson, P. (1974): “Advertising as Information," The Journal of Political Economy, $82(4), 729-754$.

[10] PigA, C. (2000): "Competition in a duopoly with sticky price and advertising," International Journal of Industrial Organization, 18(4), 595-614.

[11] Schoonbeek, L., and P. Kooreman (2007): "The Impact of Advertising in a Duopoly Game," International Game Theory Review, 9(4), 565.

[12] Stigler, G., and G. Becker (1977): "De Gustibus Non Est Disputandum," American Economic Review, 67(2), 76-90. 
[13] TRIPlett, J. (2006): Handbook on hedonic indexes and quality adjustments in price indexes: special application to information technology products. Publications de l'OCDE. 


\section{Appendix 1: Proof of propositions 3 and 4}

Proof of proposition 3: According to section 2, the advertising effort of the leader $q_{1}=1$ is at least twice the advertising effort of a Neck and Neck firm; indeed, if $\phi>\epsilon(1-f)$, $q_{0}=0$ and if $\phi<\epsilon(1-f), q_{0}=\frac{1-f-\phi / \epsilon}{1-2 f} \leq \frac{1 / 2-f}{1-2 f}=0.5$ (since $\left.\phi>\epsilon / 2\right)$. Both $q_{1}$ and $q_{0}$ are non-increasing with $f$, so non-decreasing with competition. Therefore, as $A=\phi\left(\mu_{0} 2 q_{0}+\mu_{1} q_{1}\right)=2 q_{0}+\mu_{1}\left(q_{1}-2 q_{0}\right)$, proposition 3 is straightforward if the probability of being unleveled $\mu_{1}$ is increasing with competition.

As shown in table $1, \Pi_{0}$ is always increasing with $f$ when $\phi \in[\epsilon / 2, \epsilon]$, and then $\Pi_{1}-\Pi_{0}$ is decreasing with $f$ since $\Pi_{1}$ does not vary with $\mathrm{f}$. Therefore according to equation 3 , $n_{0}$ is increasing with competition (escape competition effect). In addition, as previously noted, $n_{-1}$ is a decreasing function of $n_{0}$, while $\Pi_{1}-\Pi_{-1}=2 \epsilon-\phi$ is constant. So, from equation $5, n_{-1}$ is decreasing with competition and the ratio $\left(n_{-1}+h\right) / n_{0}$ is decreasing with competition.

But $\mu_{1}\left(n_{-1}+h\right)=2 \mu_{0} n_{0}$ and $\mu_{0}+\mu_{1}=1$. Thus $\mu_{1}=\frac{2}{2+\left(n_{-1}+h\right) / n_{0}}$ is indeed increasing with competition. QED

Proof of proposition 4: The proof proceeds in 4 steps:

1) If the $\mathrm{R} \& \mathrm{D}$ efforts $n_{0}$ and $n_{1}$ are both decreasing with $\phi$, then the total flow of innovation $I$ is also decreasing with $\phi$.

2) $n_{0}$ is decreasing with $\phi$.

3) $\frac{\partial n_{0}}{\partial \phi}$ and $\frac{\partial n_{-1}}{\partial \phi}$ have the same sign as soon as $n_{0}>n_{-1}$.

4) $n_{0}(f=1 / 2)>n_{-1}(f=1 / 2)$ and $n_{0}$ is decreasing with $f$ whereas $n_{-1}$ is increasing with $f$. Thus $n_{0}>n_{-1}$ for all $f \in[0,1 / 2]$.

1), 2), 3) and 4) clearly imply that $I$ is decreasing with $\phi$, that is, reducing the cost of advertising increases the $R \& D$ effort.

Proof of 1): $\frac{\partial I}{\partial \phi}$ and $\frac{\partial \ln (I)}{\partial \phi}$ have the same sign. Let $n_{0}^{\prime}$ and $n_{-1}^{\prime}$ denote respectively $\frac{\partial n_{0}}{\partial \phi}$ and $\frac{\partial n_{-1}}{\partial \phi}$ and assume they are negative. From equation 6 , we get: 


$$
\begin{aligned}
\frac{\partial \ln (I)}{\partial \phi} & =\frac{n_{0}^{\prime}}{n_{0}}+\frac{2 n_{-1}^{\prime}}{2 n_{-1}+h}-\frac{2 n_{0}^{\prime}+n_{-1}^{\prime}}{2 n_{0}+n_{-1}+h} \\
& \leq \frac{2 n_{0}^{\prime}}{2 n_{0}+n_{-1}+h}+\frac{n_{-1}^{\prime}}{n_{-1}+h+2 n_{0}}-\frac{2 n_{0}^{\prime}+n_{-1}^{\prime}}{2 n_{0}+n_{-1}+h} \\
& \leq 0
\end{aligned}
$$

\section{Proof of 2):}

For values of $\phi$ between $\epsilon / 2$ and $\epsilon, \Pi_{1}$ is decreasing with $\phi$ whereas $\Pi_{0}$ is increasing or constant with $\phi$. This implies that $\Pi_{1}-\Pi_{0}$ is decreasing with $\phi$. From equation $3, n_{0}$ is decreasing with $\phi$.

\section{Proof of 3):}

Differentiating equation 2 with respect to $\phi$ gives:

$n_{-1} n_{-1}^{\prime}+\left(r+h+n_{0}\right) n_{-1}^{\prime}+n_{-1} n_{0}^{\prime}-n_{0} n_{0}^{\prime}=0$

$n_{-1}^{\prime}=n_{0}^{\prime}\left(\frac{n_{0}-n_{-1}}{n_{-1}+n_{0}+r+h}\right)$ if $f>1-\frac{\phi}{\epsilon}$

\section{Proof of 4):}

The fact that $n_{0}$ is decreasing with $f$ and $n_{-1}$ increasing with $f$ are prooven in the proof of proposition 3. When $f=1 / 2, q_{0}=0$ and $\Pi_{0}=f \epsilon=\epsilon / 2$ whereas $\Pi_{1}=2 \epsilon-\phi$ remain independent of $f . \Pi_{1}-\Pi_{0}=3 \epsilon / 2-\phi . \Pi_{1}-\Pi_{-1}=2 \epsilon-\phi$.

Substracting equation 5 to equation 3 we get:

$$
\begin{aligned}
n_{0}-n_{-1}>0 & \Leftrightarrow n_{0}+\sqrt{(r+h)^{2}+3 \epsilon-2 \phi} \geq \sqrt{(r+h)^{2}+n_{0}^{2}+4 \epsilon-2 \phi} \\
& \Leftrightarrow n_{0}^{2}+(r+h)^{2}+3 \epsilon-2 \phi+2 n_{0} \sqrt{(r+h)^{2}+3 \epsilon-2 \phi} \geq(r+h)^{2}+n_{0}^{2}+4 \epsilon-2 \phi \\
& \Leftrightarrow 2 n_{0} \sqrt{(r+h)^{2}+3 \epsilon-2 \phi} \geq \epsilon \\
& \Leftrightarrow\left(-(r+h)+\sqrt{(r+h)^{2}+3 \epsilon-2 \phi}\right) \sqrt{(r+h)^{2}+3 \epsilon-2 \phi} \geq \epsilon / 2 \\
& \Leftrightarrow-(r+h) \sqrt{(r+h)^{2}+3 \epsilon-2 \phi}+(r+h)^{2}+5 \epsilon / 2-2 \phi \geq 0 \\
& \Leftrightarrow\left((r+h)^{2}+5 \epsilon / 2-2 \phi\right)^{2} \geq(r+h)^{2}\left((r+h)^{2}+3 \epsilon-2 \phi\right) \\
& \Leftrightarrow(5 \epsilon-4 \phi)(r+h)^{2}+(5 \epsilon / 2-2 \phi)^{2} \geq(r+h)^{2}(3 \epsilon-2 \phi) \\
& \Leftrightarrow 2(\epsilon-\phi)(r+h)^{2}+(5 \epsilon / 2-2 \phi)^{2} \geq 0
\end{aligned}
$$

which is true since $\phi \leq \epsilon$. QED. 


\section{Appendix 2: Results from simulations and Descriptive statistics}

Figure 6: Average sectoral flow of innovation when the degree of competition (x axis) and the cost of advertising (y axis) vary

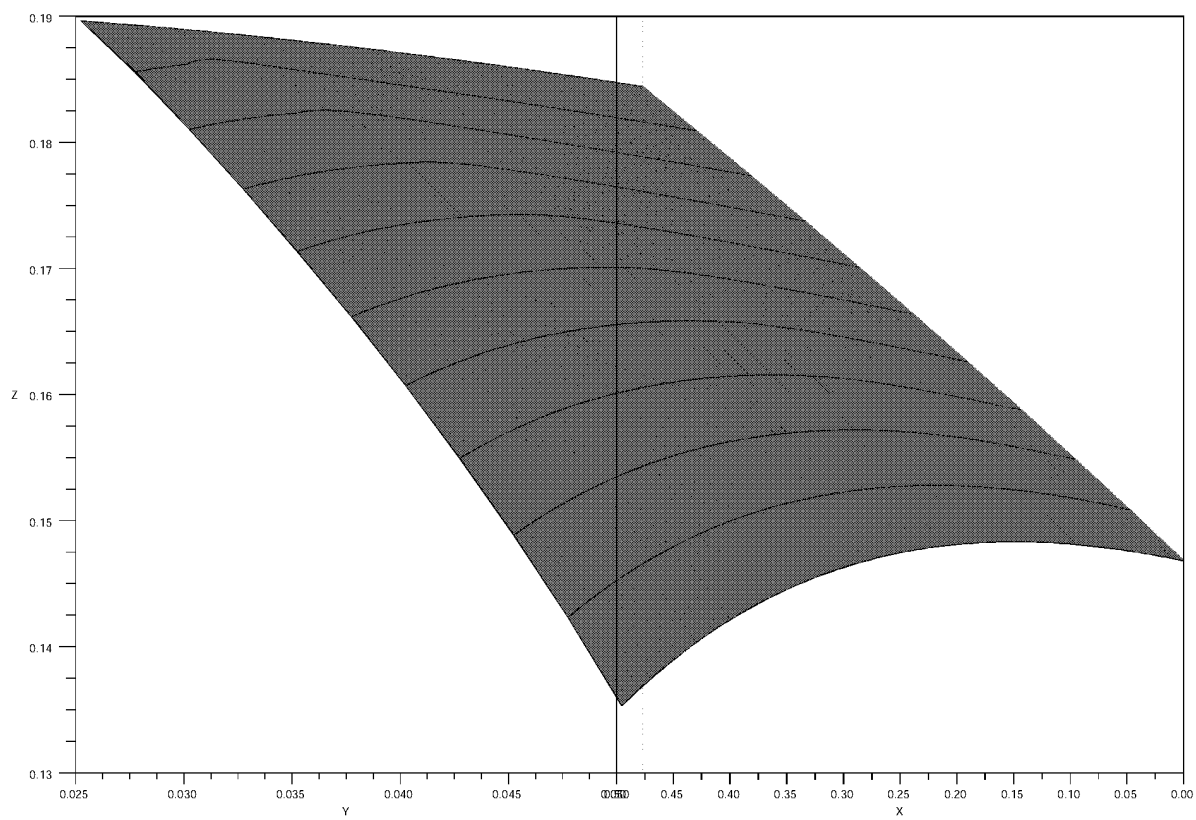




\begin{tabular}{|c|c|c|c|c|c|c|}
\hline & 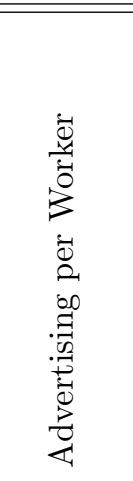 & 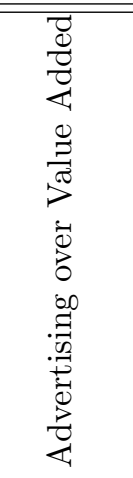 & 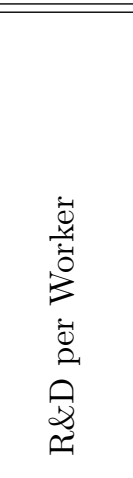 & 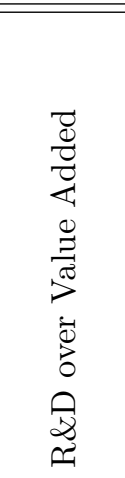 & 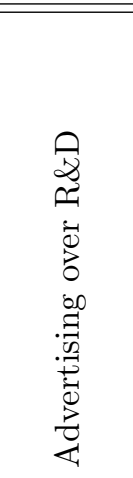 & 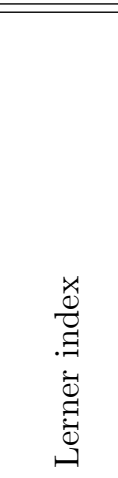 \\
\hline Agriculture, hunting, forestry and fishing & 0.912 & 0.017 & 0.354 & 0.005 & 17.560 & 0.294 \\
\hline Food and agricultural manufacturing & 4.610 & 0.075 & 0.165 & 0.003 & 100.756 & 0.197 \\
\hline Consumer goods manufacturing & 2.073 & 0.034 & 0.347 & 0.006 & 25.037 & 0.358 \\
\hline Car manufacturing & 0.726 & 0.014 & 0.591 & 0.012 & 5.915 & 0.287 \\
\hline Equipment good manufacturing & 0.679 & 0.014 & 0.741 & 0.014 & 5.272 & 0.370 \\
\hline Intermediary good manufacturing & 0.561 & 0.011 & 0.233 & 0.004 & 9.331 & 0.327 \\
\hline Energy & 2.306 & 0.023 & 0.829 & 0.008 & 9.917 & 0.242 \\
\hline Construction & 0.346 & 0.007 & 0.030 & 0.001 & 5.694 & 0.391 \\
\hline Gross and retail trade & 2.294 & 0.044 & 0.086 & 0.001 & 33.085 & 0.167 \\
\hline Transport & 0.431 & 0.009 & 0.028 & 0.000 & 14.576 & 0.348 \\
\hline Real estate & 1.828 & 0.025 & 0.065 & 0.001 & 72.593 & 0.345 \\
\hline Business sectors & 0.854 & 0.012 & 0.528 & 0.008 & 6.876 & 0.500 \\
\hline Services & 1.067 & 0.020 & 0.049 & 0.001 & 13.701 & 0.396 \\
\hline Number of observations & 480194 & 480194 & 480194 & 480194 & 56863 & 470128 \\
\hline
\end{tabular}

